Learning Outcomes Exploring our research field from first principles can help surface our underlying assumptions, as well as sensitizing researchers to the need to identify/engage with meanings important to stakeholders we seek to influence.

\section{C.002 THIS IS HOW WE DO IT: INJURY PREVENTION IN WESTERN AUSTRALIA}

Russ Milner*. Department of Health WA, East Perth, Australia

\subsection{6/injuryprev-2021-safety. 105}

Context The Department of Health (DoH) Western Australia (WA) employs a small team to oversee Injury Prevention policy within the Chronic Disease Prevention Directorate. The Injury Prevention team (the Team) contribute to the strategic direction and purchasing of programs for injury prevention. The Team partners with non-government organisations (NGOs) in WA to deliver community-based injury prevention health promotion programs (Programs).

Process Four Programs were awarded following an open-tender process in 2013, and ran 1 July 2014 - 30 June 2019. The conclusion of these contracts allowed for a systematic review of priorities, epidemiology, strengths, gaps and opportunities to improve injury prevention practice in WA. This review both internally and in consultation with the NGOs - has sharpened the focus of the Programs to meet the needs of the WA community.

Analysis The DoH used a suite of information to conduct the review, including:

- Key reports, strategic frameworks, and available research

- Service reviews

- Consultations with NGOs

- Practical knowledge and experience

Outcomes Following a preferred service provider process, $\mathrm{DoH}$ awarded four new service agreements, using innovation to address new and emerging priority areas. Key changes to each of the four programs will be presented and explained. A summary of the 'building blocks' to successful partnerships between research, policy and practice will also be suggested.

Learning Outcomes WA's approach to injury prevention will be explained, with an emphasis on the interrelationships between research, policy and practice.

\section{C.003 STATUS OF NEPAL'S LEGISLATION FOR INJURY PREVENTION AND CONTROL: A CRITICAL REVIEW}

${ }^{1}$ Puspa Raj Pant*, ${ }^{2}$ Amrit Dangi, ${ }^{2}$ Milan Dharel, ${ }^{2}$ Writu Bhatta, ${ }^{3}$ Sunil Kumar Joshi, ${ }^{1} J u l i e$ Mytton. 'University of the West of England, Bristol, UK; ${ }^{2}$ Swatantrata Abhiyan, Kathmandu, Nepal; ${ }^{3}$ Kathmandu Medical College, Kathmandu, Nepal

\subsection{6/injuryprev-2021-safety. 106}

Background A number of sustainable development goals (i.e. SDGs 3, 8, 11 and 16) can be addressed by reducing injuries and incorporating injury prevention into national legislation, plans and policies. Institutions can be more effective if national laws guide prioritisation, development and implementation of plans. No comprehensive review of policy and legislation supporting injury prevention and control in Nepal has been completed. Therefore, we systematically searched for and critically reviewed existing policy and legislative documents.

Methods Using stakeholders from government, NGOs and academia we identified laws and policies that included provisions supporting injury prevention and first response in the home, at work, on the road or in schools. Included documents were critically reviewed to explore their status, scope, and alignment with evidence-based prevention interventions.

Results of 122 documents identified, 61 met the inclusion criteria. Findings indicated that most legislation was not informed by evidence. For example, only $1 / 22$ interventions from the WHO SaveLIVES technical package for road safety was supported by legislation. There is a lack of consideration of capacity and infrastructure for legislative implementation/ enforcement and hence a lack of clarity of roles and responsibilities. Few documents considered the health economic argument, or the financial investment necessary, for implementation.

Conclusion Nepal has legal frameworks that recognise different injuries in different settings, but they could be strengthened by including objectives clearly aimed at prevention and control.

Learning Outcomes The new federal system of government in Nepal, affords multiple opportunities to support injury prevention through legislation and enforcement.

\section{C.004 SAFETY EFFECTS OF LEGISLATIVE POLICIES IN ESTONIA}

Indrek Saar*. Estonian Academy of Security Sciences, Tallinn, Estonia

\subsection{6/injuryprev-2021-safety. 107}

Background Over the last decade several safety related legislations have been adopted in Estonia. In this study I focused on the effects of mandatory smoking alarm regulation (2009), lower ignition propensity (LIP) cigarette standard (2011) and quantitative limits for tobacco products with travelers arriving to Estonia from non-European Union country (2013). The aim of the latter was to combat cigarette smuggling but it also contributed to the implementation of the World Health Organization Framework Convention on Tobacco Control which is one of the targets of Sustainable Development Goals.

Methods A time series regression analysis on monthly house fires data for 2007-2019 was conducted. To deal with the autocorrelation I estimated the models with ARIMA errors. Causal claims were established through counterfactual models.

Results I found strong intervention effects of smoking alarm and LIP cigarette interventions, both decreased the level of cigarette-related fires by $25 \%$ or more $(p<0.01)$. Quantitative limits for tobacco products were also detected to contribute to the reduction of cigarette-related fires but this evidence was weaker. Counterfactual models confirmed causal relationship between the interventions and house fires.

Conclusions The legislative policies examined in this study have reduced the level of house fires in Estonia.

Learning Outcomes While it was expected that smoking alarm or LIP cigarette regulations affect the house fires, the fire safety effect of border control regulation was an interesting finding. It shows that the legislative measures against illicit trade can also induce other positive safety effects. 